MENDONÇA, F.V.S.; MENEZES, J.B.; GOIS, V.A.; NUNES, G.H.S.; SOUZA, P.A.S.; MENDONÇA JÚNIOR, C.F. Armazenamento refrigerado de melão Orange Flesh. Horticultura Brasileira, Brasília, v.23, n.1, p.15-18, jan.-mar. 2005.

\title{
Armazenamento refrigerado de melão Orange Flesh
}

\author{
Fábio Vinícius de S. Mendonça; Josivam B. Menezes; Vilson A. de Gois; Glauber Henrique de S. Nunes; \\ Pahlevi Augusto de Souza²; Cledionor F. de Mendonça Júnior ${ }^{1}$ \\ ESAM, NEP, C. Postal 137, 59.625-900 Mossoró-RN; E-mail: fabiovsm45@hotmail.com; ${ }^{1}$ Estudante de graduação em Agronomia da \\ ESAM; ${ }^{2}$ Doutorando em Fitotecnia da UFV.
}

\section{RESUMO}

A vida útil pós-colheita de melões Orange Flesh tipo Honey Dew genótipo ‘AF-1749’ foi avaliada, estudando-se características visuais, físicas e físico-químicas dos frutos em pós-colheita em ensaio conduzido na Escola Superior de Agricultura de Mossoró (RN), Brasil. Utilizou-se um esquema fatorial $3 \times 5$ (temperatura $\mathrm{x}$ tempo de armazenamento) em delineamento experimental inteiramente casualizado com cinco repetições de dois frutos por parcela. Os frutos foram mantidos a uma umidade relativa de $90 \pm 5 \%$ e as temperaturas do ensaio foram de $5^{\circ} \mathrm{C}, 7^{\circ} \mathrm{C}$ e ambiente. Foram feitas avaliações em intervalos de sete dias determinando-se a firmeza da polpa, perda de massa, aparências externa e interna, conteúdo de sólidos solúveis, acidez total titulável e pH. Foi observada perda de peso e de firmeza da polpa mais acentuadas à temperatura ambiente. Os frutos armazenados às temperaturas de $5^{\circ} \mathrm{C}$ e $7^{\circ} \mathrm{C}$, mantiveram qualidade comercial até aos 28 dias. Não houve nenhum efeito da temperatura sob o conteúdo de sólidos solúveis.

Palavras-chave: Cucumis melo L., pós-colheita, qualidade.

\begin{abstract}
Cold storage of Orange Flesh melon

The postharvest shelflife of Honey Dew melons (Orange Flesh), genotype 'AF-1749', was evaluated through visual, physical, and physical-chemical traits carried out at the Escola Superior de Agricultura de Mossoró, RN, Brazil. A 3 x 5 (temperature x time of storage) factorial scheme in a completely randomized design with five replications and two-fruits plots was utilized. Fruits were kept at $90 \pm 5 \%$ relative humidity and experimental temperatures of $5^{\circ} \mathrm{C}$, $7^{\circ} \mathrm{C}$ and room temperature. Evaluations were done at 7-day intervals to determine flesh firmness, weight loss, external and internal appearances, soluble solids content, total titratable acidity and $\mathrm{pH}$. Weight loss and pulp firmness were more accentuated at room temperature. The fruits stored under temperatures of $5^{\circ} \mathrm{C}$ and $7^{\circ} \mathrm{C}$, maintained commercial quality up to 28 days. Storage temperature had no effect on the soluble solids content.
\end{abstract}

Keywords: Cucumis melo L., postharvest, quality.

(Recebido para publicação em 25 de setembro de 2003 e aceito em 16 de novembro de 2004)

$\mathrm{E}$ m 2000 ,o melão contribuiu com $6,8 \%$ do total arrecadado com as exportações de frutos no Brasil (SECEX/ MDIC, 2001). O mercado externo para o melão brasileiro está atualmente concentrado na Holanda, Reino Unido e Finlândia, que juntos importam cerca de $66,7 \%$. Outra parcela (18\%), é absorvida pelo Mercosul (Agrianual, 2001). Em 1998 a região Nordeste respondeu por 95\% da produção total de melão do Brasil, sendo o Rio Grande do Norte o principal produtor brasileiro com $65,0 \%$ (Agrianual, 2001). Com o advento da irrigação, o estado do Rio Grande do Norte vem se constituindo num dos principais polos exportadores de frutas tropicais, em especial o melão.

O melão Orange Flesh colhido no agropolo Mossoró-Assu (RN), apresenta uma boa aceitação nos mercados interno e externo, pelo alto nível de sólidos solúveis totais. Entretanto, a sua curta vida útil pós-colheita, dificulta sua comercialização, restando aos produtores o uso de técnicas pós-colheitas para aumentar sua vida útil. Dentre as técni- cas mais utilizadas, a de melhor resultado é a refrigeração. Aos produtores é recomendado que o melão Orange Flesh seja armazenado e transportado a temperaturas variando de 5 a $7^{\circ} \mathrm{C}$. A temperatura de armazenamento ideal depende da cultivar. Observam-se sérios problemas na cadeia de frio para armazenamento do melão, fazendo com que o produto colhido chegue ao mercado com qualidade insatisfatória. As causas principais da redução na qualidade são: a inexistência de préresfriamento e armazenamento refrigerado na fazenda, o transporte em condições inadequadas para o porto e transporte marítimo com os frutos a granel. Com a utilização de operações inadequadas de pós-colheita, é comum ocorrer antecipação da colheita na tentativa de prolongar a vida útil dos frutos.

O presente trabalho teve como objetivo avaliar a vida útil pós-colheita de melões Orange Flesh genótipo 'AF1749', sob três temperaturas de armazenamento, buscando adequar uma melhor temperatura de armazenamento.

\section{MATERIAL E MÉTODOS}

A cultivar 'AF-1749' da AgrofloraSakata, é recomendada para o mercado externo e, segundo a empresa produtora das sementes, caracteriza-se por sua boa aparência, coloração de polpa salmão, casca creme, flavor peculiar, peso médio entre 1,5 e $1,8 \mathrm{~kg}$, formato arredondado, pequena cavidade de sementes, conteúdo de sólidos solúveis entre 11 e $13 \%$, polpa macia e firme.

Os frutos foram obtidos em um plantio experimental localizado na fazenda São João, no agropolo Mossoró-Assú, produzidos de acordo com as práticas culturais usuais na região, utilizando-se sistema de irrigação localizada, por gotejamento, em um Latossolo Vermelho-Amarelo. Nos meses de agosto e setembro, período de cultivo, o clima dessa região é quente e seco, com precipitação pluviométrica anual de 423 mm e temperatura média mensal de $31^{\circ} \mathrm{C}$. Colheu-se os frutos tipo 6 (6 frutos por caixa), no estádio de maturação 


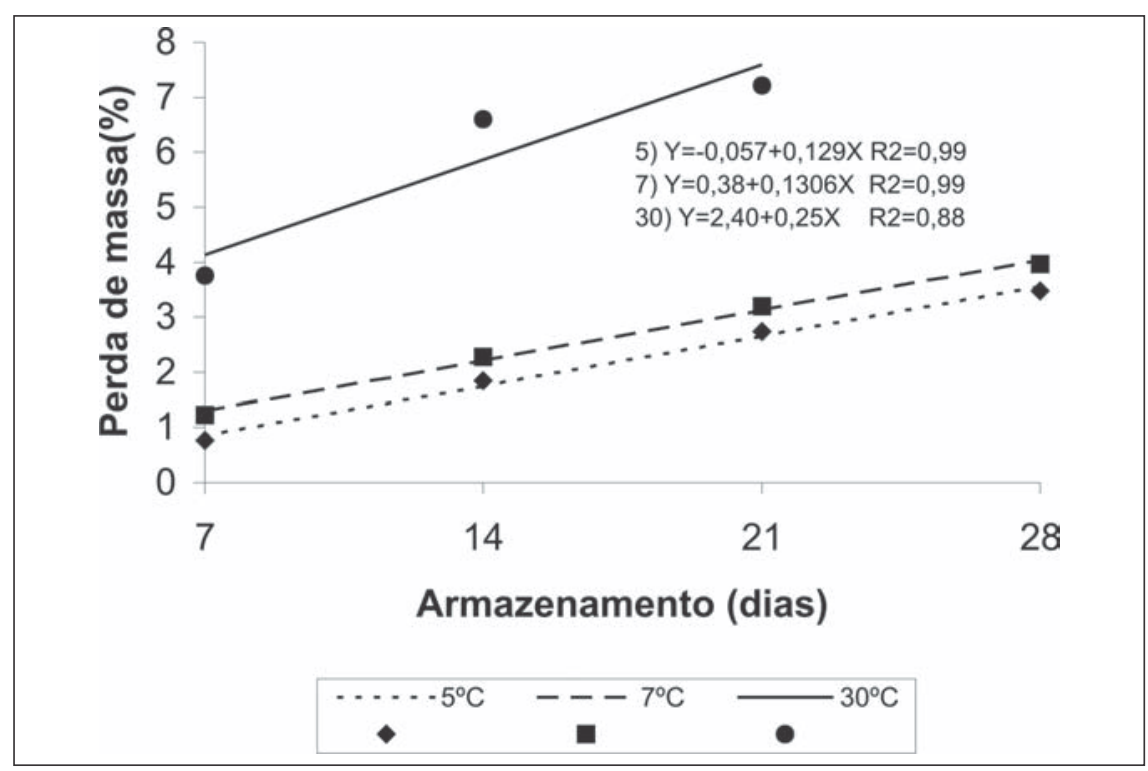

Figura 1. Valores médios para perda de massa de melão Orange Flesh ‘AF-1749’ armazenado a três temperaturas. Mossoró, ESAM, 2001.

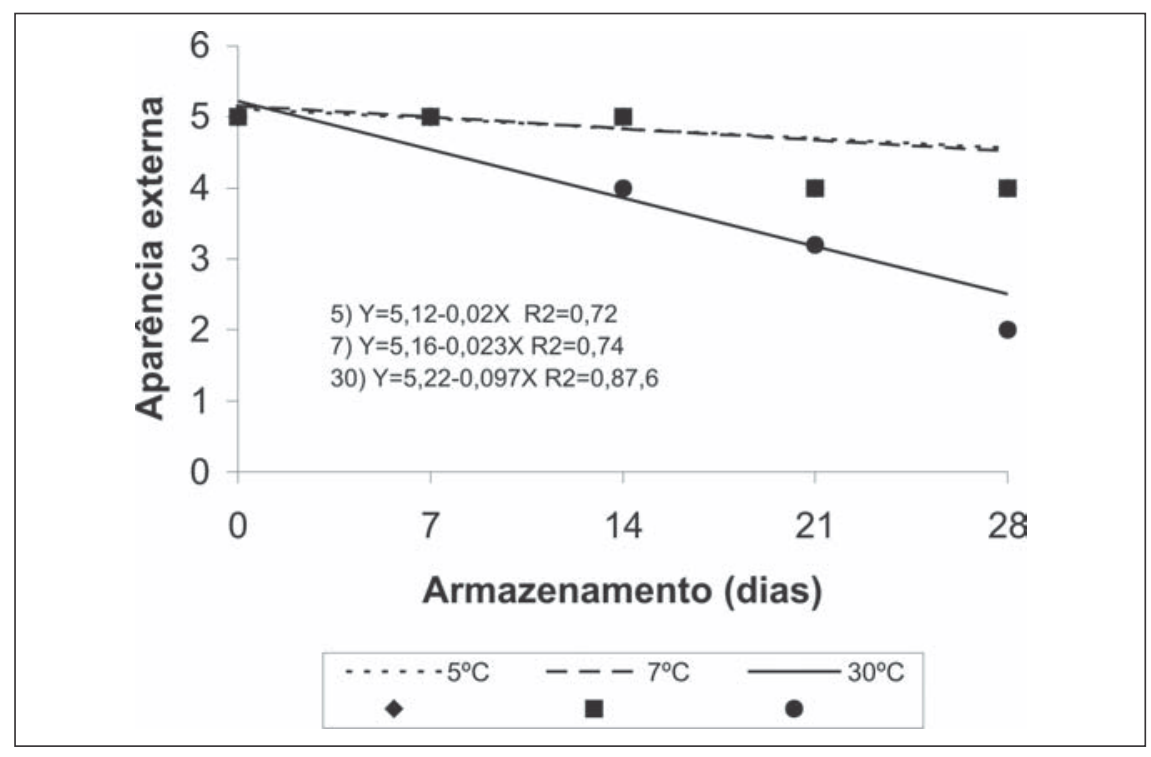

Figura 2. Valores médios para aparência externa de melão Orange Flesh ‘AF-1749’ armazenado a três temperaturas. Mossoró, ESAM, 2001.

comercial. Após a colheita, os frutos foram levados ao laboratório da ESAM, onde foram selecionados (eliminou-se os frutos com imperfeições), pesados e armazenados imediatamente nas temperaturas ambiente $\left(30+2^{\circ} \mathrm{C}\right.$ e UR $\left.50 \%\right) \mathrm{e}$ em câmaras refrigeradas com temperaturas de $5+1^{\circ} \mathrm{C}$ e $7+1^{\circ} \mathrm{C}$, com umidade relativa de $90+5 \%$, por 28 dias, tendo sido de 7 horas o intervalo entre a colheita e o armazenamento.

$\mathrm{O}$ ensaio foi conduzido em delineamento inteiramente casualizado com quinze tratamentos, resultante da com- binação fatorial $3 X 5$, (três temperaturas de armazenamento: ambiente, próximo a $30+2^{\circ} \mathrm{C} ; 5+1{ }^{\circ} \mathrm{C}$ e $7+1{ }^{\circ} \mathrm{C}$ ) e cinco períodos de armazenamento $(0 ; 7 ; 14$; 21 e 28 dias), sendo a parcela composta de 2 frutos, com 5 repetições para cada tempo de armazenamento.

A perda de massa foi calculada em relação ao peso inicial por ocasião da colheita e os pesos obtidos em cada intervalo de armazenamento, sendo os resultados expressos em percentagem. As avaliações de aparência externa (depressões, murcha ou lesões fúngicas) e aparência interna (colapso interno, sementes soltas ou presença de líquido) foram feitas por três técnicos treinados utilizando-se uma escala visual e subjetiva, segundo a classificação utilizada por Gomes Júnior et al. (2000), considerando-se a ausência ou presença de defeitos ( 1 = fruto extremamente marcado pelos defeitos anteriormente destacados; $2=$ severo; $3=$ médio; 4 = leve; 5 = ausência dos defeitos). Quando a nota obtida foi $£ 3,0 \mathrm{o}$ fruto foi considerado indesejável para o consumo e eliminado das análises. Para a avaliação da firmeza de polpa, o fruto foi dividido longitudinalmente, sendo que, em cada uma de suas metades, foram realizadas duas leituras (na parte mediana da polpa do fruto) com um penetrômetro de marca Mc Cormick modelo FT 327 (valor máximo de leitura de 30 Lbf.) com adaptador de $8 \mathrm{~mm}$ de diâmetro, sendo os resultados obtidos em libras (Lbf) e transformados para Newton (N), utilizando-se o fator de conversão de 4,45. O teor de sólidos solúveis totais (SST) foi determinado por refratometria, utilizando-se um suco filtrado oriundo de fatias da polpa do melão, homogeneizadas em liquidificador doméstico e fazendo-se a leitura do filtrado em um refratômetro digital modelo PR - 100 Palette, com correção automática de temperatura (escala de 0 a $32 \%$ ) e os resultados foram expressos em porcentagem, conforme a metodologia proposta por Kramer (1973). A acidez total titulável (ATT) foi determinada em duplicata, utilizando-se de uma alíquota de $10 \mathrm{ml}$ de suco, ao qual se adicionaram $40 \mathrm{ml}$ de água destilada e 5 gotas de fenolftaleína alcoólica a $1 \%$. A seguir titulou-se até o ponto de viragem com solução de $\mathrm{NaOH}$ a $0,1 \mathrm{~N}$, previamente padronizada, sendo os resultados expressos em \% de ácido cítrico de suco. O potencial hidrogeniônico $(\mathrm{pH})$ foi determinado em duplicata, utilizando-se um potenciômetro digital modelo DMPH - 2 Digimed.

Os resultados foram submetidos à análise de variância através do software SAS (Statistical Analisys Systen) por meio dos procedimentos PROC GLM e PROC REG.

\section{RESULTADOS E DISCUSSÃO}

Verificou-se uma variação significativa em função do tempo de 
armazenamento, na perda de massa (Figura 1). Essa modificação foi caracterizada por um aumento gradual durante o período de armazenamento, atingindo valores mais altos quando armazenados a temperatura ambiente, $7,22 \%$ aos 21 dias, enquanto que a $5^{\circ} \mathrm{C}$ e $7^{\circ} \mathrm{C}$ atingiram, respectivamente, 3,47 e $3,97 \%$ aos 28 dias de armazenamento. A perda de massa pode ser atribuída, principalmente, à perda de umidade e de material de reserva pela evapotranspiração e respiração, respectivamente, sendo um dos principais fatores limitante para vida útil pós-colheita dos frutos e hortaliças, sofrendo, esses, influência de inúmeros fatores, como cultivar, tratamentos pós-colheita, condições ambiente e duração do armazenamento, entre outros (Gonçalves et al., 1996; Mayberry e Hartz, 1992).

Gomes Júnior et al. (2000), trabalhando com armazenamento refrigerado de melões 'Hy Mark', observaram uma perda de massa de 3,95\% e 6,0\%, respectivamente para temperaturas de $5^{\circ} \mathrm{C}$ e $10^{\circ} \mathrm{C}$ ao final de 35 dias de armazenamento.

Foi observada interação significativa para as aparências externa e interna em função do armazenamento (Figura 2 e 3). A modificação, nas notas de aparência, durante o armazenamento foi caracterizada por um decréscimo gradativo mais acentuado quanto mais elevada a temperatura. Os frutos armazenados à temperatura ambiente tiveram uma vida útil de 21 dias enquanto que os frutos mantidos a 5 e $7^{\circ} \mathrm{C}$ atingiram 28 dias com boa qualidade comercial. Em estudos realizados por Mendonça et al. (2000), trabalhando com melão Galia 'Galileu', foi verificado que até aos 24 dias, os frutos armazenados a 6 e $10^{\circ} \mathrm{C}$ obtiveram notas superiores a 3 , possibilitando sua comercialização. $\mathrm{O}$ tempo de vida útil pós-colheita, superior a 25 dias (7 dias em câmara fria/container durante a permanência na fazenda, transporte para o porto e carregamento; 11 dias para o transporte marítimo e 7 dias para o desembarque e distribuição para os supermercados), é suficiente para a comercialização do melão visando o mercado europeu (Menezes, 1996).

A firmeza de polpa caracterizou- se pelo decréscimo gradual e significativo, dos valores referentes a essa característica, ao longo do período de

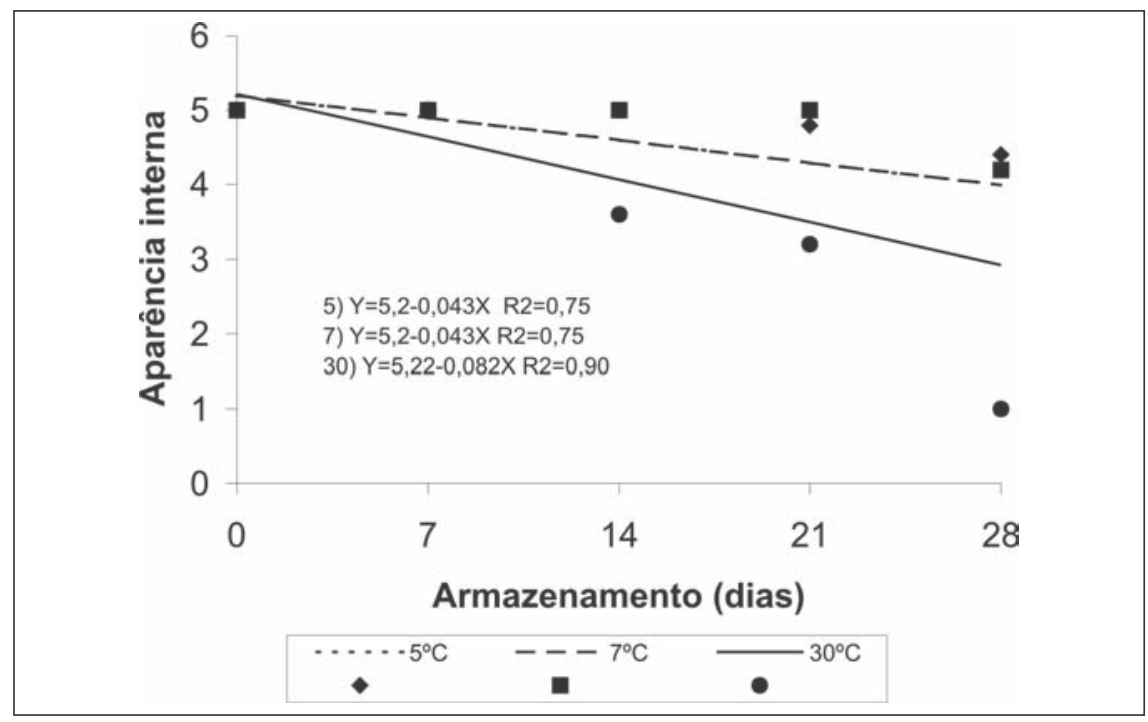

Figura 3. Valores médios para aparência interna de melão Orange Flesh 'AF-1749' armazenado a três temperaturas. Mossoró, ESAM, 2001.

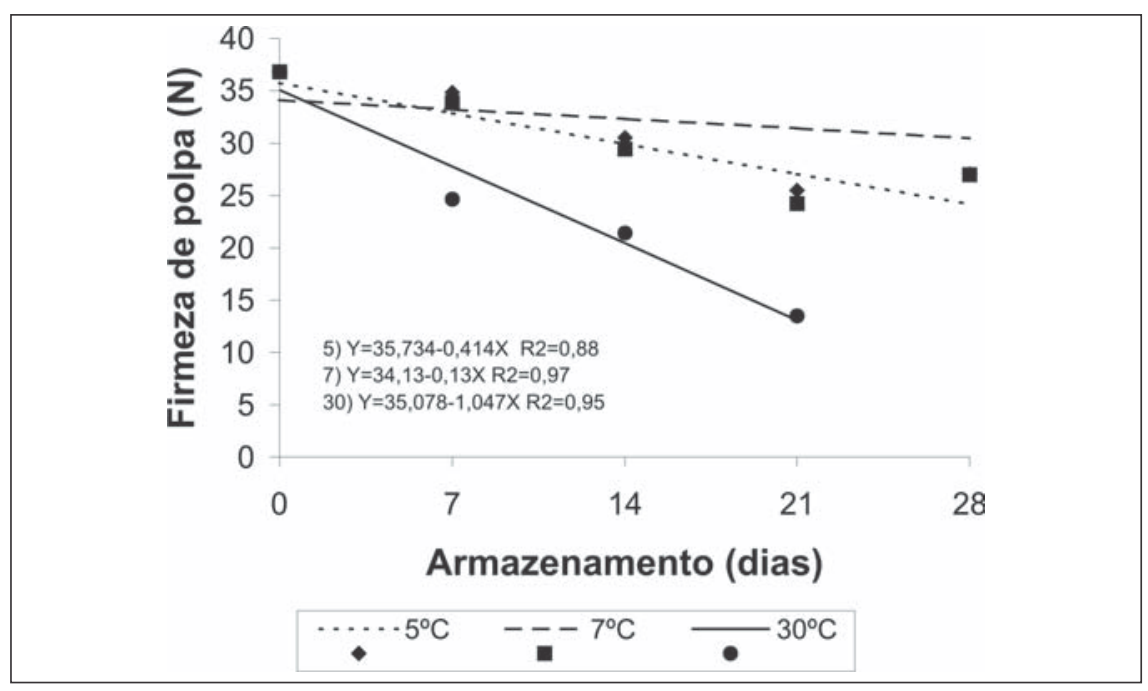

Figura 4. Valores médios para firmeza de polpa de melão Orange Flesh 'AF-1749' armazenado a três temperaturas. Mossoró, ESAM, 2001.

armazenamento (Figura 4). Por ocasião da colheita, a firmeza da polpa foi de 35 $\mathrm{N}$, em média, sendo que ao final dos 21 dias os frutos do tratamento a temperatura ambiente apresentaram uma firmeza da polpa de $13,09 \mathrm{~N}$, enquanto que os tratamentos a $5^{\circ} \mathrm{C}$ e $7^{\circ} \mathrm{C}$ chegaram ao final dos 28 dias de armazenamento com $24,14 \mathrm{~N}$ e $30,09 \mathrm{~N}$, respectivamente. Portela e Cantwell (1998), trabalhando com quatro tipos de melões Honey Dew (Green Flesh; Morning Ice; Rico e RML 2704) verificaram valores iniciais de 15 a $20 \mathrm{~N}$ e finais de 6 a $12 \mathrm{~N}$.

A perda de firmeza é uma característica geral do processo de amadure- cimento em diversos frutos, incluído o melão que se caracteriza pelo amaciamento durante o armazenamento. A tendência geral dos frutos, durante a pós-colheita, é um declínio na firmeza condicionada por diversos fatores que, em melão, tem sido atribuído principalmente, à hidrólise de polissacarídeos da parede celular e à degradação enzimática de compostos pécticos da lamela média (Salunke e Desai, 1984). A firmeza é essencial no manuseio pós-colheita, em razão dos frutos mais firmes terem maior resistência a injúrias mecânicas sofridas durante o transporte e a comercialização (Grangeiro, 1997). 
Não se verificou diferença significativa para o conteúdo de sólidos solúveis totais, sendo que os valores médios nas temperaturas ambiente, $5^{\circ} \mathrm{C}$ e $7^{\circ} \mathrm{C}$ foram de $8,74 \%, 9,01 \%$ e $8,99 \%$, respectivamente. Os frutos obtiveram valores acima de 9,00\% e menores que $12,00 \%$, sendo com isso ideais para a comercialização no mercado externo (Gayet, 1994). Fernandes (1996), estudando melão Orange Flesh, também não observou efeito significativo para os teores de sólidos solúveis. Segundo Alves et al. (2000), quanto mais doce o melão, melhor será o seu valor de mercado. A definição do ponto de colheita mínimo, desde que respeitados os padrões, deve ser feita com base no prazo necessário para que o produto chegue ao mercado de destino, tendo sempre em mente que o melão pode se tornar mais macio, a cor da casca pode modificar, mas não haverá aumento de sólidos solúveis depois da colheita.

Houve diferença significativa para a acidez total titulável (ATT), sendo que esta variação não gradual deve-se à heterogeneidade dos frutos analisados. Os valores médios obtidos foram de $0,160,0,176$ e $0,181\left[\left(\right.\right.$ mmoles $\left.\left.\mathrm{H}^{+}\right) / \mathrm{L}\right]$ para as temperaturas ambiente, $5^{\circ} \mathrm{C}$ e $7^{\circ} \mathrm{C}$, respectivamente. Porém, Ermland Júnior (1986) trabalhando com o armazenamento sob condições ambiente do melão 'Valenciano Amarelo CAC', não verificou alteração no ATT durante o período de análises.

$\mathrm{Na}$ avaliação do pH não se verificou diferença significativa. Os valores médios foram de $6,15,5,98$ e 5,90 para as temperaturas ambiente, $5^{\circ} \mathrm{C} \mathrm{e} 7{ }^{\circ} \mathrm{C}$, respectivamente. Isto pode ser explicado pela capacidade tamponante dos sucos de frutas, podendo ocorrer variações na ATT, sem variações apreciáveis no $\mathrm{pH}$ (Chitarra e Chitarra, 1990). Os valores obtidos nas análises de $\mathrm{pH}$ variaram de 5,89 na ocasião da colheita a 5,90 ao final dos 28 dias de armazenamento. Trabalhando com melões Orange Flesh, Fernandes (1996) observou um pH médio de 6,23. Porém, Carvalho et al. (1995), trabalhando com melão Amarelo 'Yellow King' observou uma pequena elevação no nível de pH, em decorrência da redução da ATT, embora não tenha sido estatisticamente significativo.

Com base nos resultados obtidos, conclui-se que o melão Orange Flesh, 'AF-1749', possui uma vida útil póscolheita de no mínimo 28 dias sob temperaturas de armazenamento de $5^{\circ} \mathrm{C}$ e $7^{\circ} \mathrm{C}$, mostrando o efeito que a refrigeração exerce no armazenamento desse fruto. Observou-se resultados semelhantes nas temperaturas de $5^{\circ} \mathrm{C}$ e $7^{\circ} \mathrm{C}$, durante todo o ensaio, mostrando serem suficientes para manter a qualidade dos frutos durante o tempo necessário para a exportação.

\section{AGRADECIMENTOS}

Ao convênio ESAM/ VALEFRUTAS/CNPq-PADFIN, pelos recursos financeiros. À Fazenda São João S.A., pelos frutos cedidos.

\section{LITERATURA CITADA}

AGRIANUAL. Anuário da agricultura brasileira. FNP Consultoria \& Comércio, 2001. 545 p.

ALVES, R.E. Melão: pós-colheita. Brasília, DF: Embrapa, 2000. 43 p. (Comunicação para transferência de Tecnologia).

CHITARRA, M.I.F.; CHITARRRA, A.B. Póscolheita de frutos e hortaliças fisiologia e manuseio. Lavras-MG: ESAL FAEP, 1990. 289 p.

CARVALHO, H.A.; CHITARRA, M.I.F.; CHITARRA, A.B.; MENEZES, J.B. Vida útil póscolheita de melão 'Yellow King'. Revista Brasileira de Fruticultura, Cruz das Almas, v.17, n.3, p.111-118, 1995.
ERMLAND JÚNIOR, F.K.V. Efeito do cultivo em casa de vegetação com cobertura de filme de polietileno sobre a qualidade tecnológica e conservação pós-colheita de melão (Cucumis melo L.) $c v$. Valenciano Amarelo CAC, com uso de irrigação por jato-pulsante. 1986. $46 \mathrm{f}$. (Trabalho graduação) - UNESP, FCAV, Jaboticabal.

FERNANDES, P.M.G.C. Armazenamento ambiente e refrigerado de melão, híbrido Orange Flesh, submetido à aplicação pós-colheita de cloreto de cálcio. 1996. 68 f. (Tese mestrado) UFLA, Lavra.

GAYET, J.P. Características das frutas de exportação. In: NETO, A.G. (Ed.). Melão para a exportação: procedimento colheita e pós-colheita. Brasília: MAARA/FRUPEX, 1994. p.11-21.

GOMES JÚNIOR, J.; MENEZES, J.B.; SOUZA, P.A.; GUIMARÃES, A.A.; SIMÕES, A.N Armazenamento refrigerado de melão 'Hy Mark'. In: CONGRESSO BRASILEIRO DE OLERICULTURA, 40., 2000, São Pedro, Anais... São Pedro: SOB, 2000.

GONÇALVES, F.C.; MENEZES, J.B.; ALVES, R.E. Armazenamento de melão "Piel de Sapo" sob condições ambiente. Horticultura Brasileira, Brasília, v.14, n.1, p.49-52, 1996.

GRANJEIRO, L.C. Densidade de plantio em hibridos de melão amarelo. 1997. 48 f. (Tese mestrado) - ESAM, Mossoró.

KRAMER, A. Fruits and Vegetables. In: KRAMER, A.; TWIGG, B.A. (Ed.) Quality Control for the Food Industry. Connecticut: Avi Publishing Company, 1973. v.2, p.157-227.

MAYBERRY, K.S.; HARTZ, T.K. Extension of muskmelon storage life through the use of hot water treatment and polyethilene wraps. HortScience, v.27, n.4, p.324-326, 1992.

MENDONÇA, F.V.S.; GOMES JÚNIOR, J.; MENEZES, J.B.; ARAUUJO, J.M.M.; OLIVEIRA, M. Armazenamento refrigerado de melão Galia 'Galileu'. Horticultura Brasileira, Brasília, v.18, julho 2000. Suplemento. Revista. Trabalho apresentado no $40^{\circ}$ Congresso Brasileiro de Olericultura, 2000

MENEZES, J.B. Qualidade pós-colheita de melão tipo Galia durante a maturação e o armazenamento. 1996. 157 f. (Tese doutorado) UFLA, Lavras.

PORTRELA, S.I.; CANTWELL, M.I. Quality of minimally processed Honeydew melons stored in air or controlled atmosphere. Postharvest Biology and Technology. p.351-357, 1998.

SALUNKHE, D.K.; DESAI, B.B. Postharvest Biotechnology of fruits. Boca Raton: CRC Press, 1984. v.1, p.77-93.

SECEX/MDIC. Secretaria de Comércio Exterior/ Ministério do Desenvolvimento, Indústria e Comércio. Exportações Brasileiras de Frutas. Disponível em: < http:www.mdic.gov.br $>$. Acesso em 19 mai 2001. 